\title{
IFIH1-GCA-KCNH7 locus is not associated with genetic susceptibility to multiple sclerosis in French patients
}

\author{
Nicolas Couturier ${ }^{1}$, Pierre-Antoine Gourraud ${ }^{2}$, Isabelle Cournu-Rebeix ${ }^{3}$, Claire Gout ${ }^{3}$, \\ Florence Bucciarelli ${ }^{1}$, Gilles Edan ${ }^{4}$, Marie-Claude Babron ${ }^{5}$, Françoise Clerget-Darpoux ${ }^{5}$, \\ Michel Clanet ${ }^{1}$, Bertrand Fontaine ${ }^{3}$ and David Brassat*,1
}

\begin{abstract}
${ }^{1}$ INSERM U563, and Pôle des neurosciences, Université Toulouse 3, Toulouse, France; ${ }^{2}$ INSERM U558, Département d'épidémiologie et de santé publique, Université Toulouse 3, Toulouse, France; ${ }^{3}$ INSERM U546, Faculté de Médecine Pitié-Salpêtrière, Paris, France; ${ }^{4}$ Département de Neurologie, CHU Pontchaillou, Rennes, France; ${ }^{5}$ INSERM U535, Université de Paris Sud, Villejuif, France
\end{abstract}

A recent investigation reported, for the first time, an association between variants in the IFIH1-GCA-KCNH7 locus and multiple sclerosis (MS). We sought to replicate this genetic association in MS with a new independent MS cohort composed of French Caucasian MS trio families. The two most significant IFIH1 single nucleotide polymorphisms, rs 1990760 and rs2068330, reported as involved in MS susceptibility, were genotyped in 591 French Caucasian MS trio families, and analyzed using the transmission/disequilibrium test. No association with MS was found (rs1990760, $P=0.45$ and rs2068330, $P=0.27$ ). Similarly, no significant association was detected after stratification for HLA-DRB1*1501 carriers. Reasons that may explain this discrepancy between the original report and our study are discussed.

European Journal of Human Genetics (2009) 17, 844-847; doi:10.1038/ejhg.2008.259; published online 21 January 2009

Keywords: IFIH1; multiple sclerosis; interferon-induced protein; autoimmune disease; genetic association study

\section{Introduction}

Multiple sclerosis (MS) is a major cause of disability in young adults. MS pathogenesis is not well understood but there is a large body of evidence for an autoimmune process triggered by environmental factors in susceptible individuals. ${ }^{1}$ Genetic factors in MS have been suggested by epidemiological studies ${ }^{2}$ and a strong genetic effect was pointed out more than 30 years ago with the HLA-DR2 locus. It is only recently that non-HLA variants (IL7R and

*Correspondence: Professor D Brassat, INSERM U563 - CPTP, Equipe Autoimmunité et Immunorégualtion, CHU Purpan - BP3028, 31024 Toulouse, France.

Tel: + 335627445 14; Fax: + 335627445 58;

E-mail: dbrassat@yahoo.fr

Received 5 June 2008; revised 22 October 2008; accepted 2 December 2008; published online 21 January 2009
$\mathrm{IL}_{2 \mathrm{R}}{ }^{3}$ and IL7R variants ${ }^{4,5}$ ) have been implicated with strong confidence in a genuine but small effect (odds ratio $=1.2$ with $P=5.84 \times 10^{-12}$ ) in a combined approach for IL7R. ${ }^{6}$ These findings have already been replicated in populations with other ethnic backgrounds. ${ }^{7,8}$ Unfortunately, before the IL7R reports, almost 30 years passed with a putative locus pinpointed by one study but not replicated by others. The reasons why it is difficult to confirm a positive genotype-phenotype association result are now well established, and recent outstanding guidelines for replication have been proposed by an NCI-NHGRI working group. ${ }^{9}$ An alternative to replication, the so-called combination approach, has been proposed. ${ }^{6,10,11}$ Both the replication and combination methods need to take positive and negative studies into account to overcome a well-known bias toward positive results. Here, we failed 
to replicate a Spanish, case-control, positive association between the IFNIH1-GCA-KCNH7 locus and $\mathrm{MS}^{12}$ in an independent French cohort with a family-based approach.

\section{Subjects and methods Patients}

In total 591 French Caucasian trio families composed of one affected subject and the two parents (with four European Caucasian grandparents) were recruited through a national media campaign followed by the selection of individuals who satisfied the criteria for MS. ${ }^{13-15}$ All the subjects gave their informed consent, and the 'Comite consultatif de protection des personnes dans la recherche biomédicale Paris-Pitié-Salpêtrière' approved the study. For affected individuals, the F/M sex ratio was 2.3:1 with 412 women and 176 men. For three patients, no gender information was available. HLA-DRB1*1501 genotype was available from $368 \mathrm{MS}$ patients. In these MS patients, $52 \%$ carried at least one HLA-DRB1*1501 allele (DRB1* $1501^{+/+}$ or DRB1* $1501^{+/-}$).

\section{Molecular genotyping method}

Genomic DNA was purified from fresh peripheral blood leukocytes by standard methods. We genotyped genetic variants, using a TaqMan $5^{\prime}$ allele-discrimination assay (Applied Biosystems, Foster City, CA, USA). The PCR was performed in a total reaction volume of $5 \mu \mathrm{l}$, with the following amplification protocol: denaturation at $95^{\circ} \mathrm{C}$ for $10 \mathrm{~min}$, followed by 40 cycles of denaturation at $92^{\circ} \mathrm{C}$ for $15 \mathrm{~s}$ and annealing and extension at $60^{\circ} \mathrm{C}$ for $1 \mathrm{~min}$. After the PCR procedure, the genotype of each sample was attributed automatically by measuring the allele-specific fluorescence. An ABI Prism 7900 Sequence detection system and the SDS 2.2.2 software (both from Applied Biosystems) were used for allele discrimination.

The percentages of nonmissing genotypes were 99.4 and $99.3 \%$ for rs1990670 and rs2068330, respectively.

\section{SNP characteristics}

Two polymorphisms in the IFIH1-GCA-KCNH7 locus, present on chromosome 2q24.3, were genotyped in 591 French Caucasian MS patients and in the two parents of each patient. The first selected polymorphism, rs1990670 (ID no. C__2780299_30) is located in exon 15 of the IFIH1 gene (leading the A946T substitution). The second one, rs2068330 (ID no. C__15862240_10), in the $3^{\prime}$ boundary of this locus, is located in intron 14 of the KCNH7 locus. Minor allele frequency is 39.6 and $36.4 \%$ for rs1990670 and rs2068330, respectively. These two polymorphisms were chosen with regard to previous studies where they have been shown to be associated with T1D, Graves' disease and MS.

\section{Statistical analysis}

In accordance with the recommendations of the NCI-NHGRI workgroup, the association analysis of the IFIH1-GCA-KCNH7 locus was performed by means of the transmission/disequilibrium test (TDT), using the Haploview program. ${ }^{16}$ TDT compares the transmission of single nucleotide polymorphism (SNP) alleles from heterozygous parents to affected offspring with Mendel's expectation (50\%), using a bilateral $\chi^{2}$-test with 1 d.f.. $P$-values under 0.05 were considered as statistically significant. The genetic power of our population for detecting a genotype relative risk of 1.73 (homozygotes) and 1.16 (heterozygotes) was calculated with the genetic power calculation test (http://pngu.mgh.harvard.edu/ purcell/gpc/dtdt.html). The expected power for a type I error of $5 \%$ is $79.5 \%$ for our samples of 591 trios. As we performed a replication study, a type I error of $10 \%$ is acceptable (one way study). In this case, the power of our population is $87.3 \%$.

To facilitate comparison between our data and those of Martinez et al, we reformed our samples as case-controls using the parents as a control cohort (see Table 1).

\section{Results}

Both variants, rs1990670 and rs2068330, were in HardyWeinberg equilibrium in the control population derived from the nontransmitted parental chromosomes. Individually, neither of these two polymorphisms in the IFIH1GCA-KCNH7 locus showed a significant association with MS susceptibility in the TDT test. The allele A of polymorphism rs19907660 was nonsignificantly overtransmitted (Table 2) and rs2068330 polymorphism did not show significant overtransmission of the allele $\mathrm{C}$ to MS patients even though it was the best marker from a statistical point of view (Table 3 ).

As reported in previous studies, we observed strong linkage disequilibrium between the SNP located in the IFH1 gene (rs1990760) and the SNP in the KCNH7 gene (rs2068330): $D^{\prime}=0.85$ and $r^{2}=0.63$. The analysis of haplotypes showed that three of the four possible haplotypes had a frequency higher than 5\% in our population but no haplotype was significantly associated with MS susceptibility (Table 4).

HLA-DRB1*15 genotype was available from 368 MS patients. To assess the influence of the HLA locus, we subdivided the MS patients into two groups according to their HLA-DRB1*1501 positivity: the first group was composed of HLA-DR ${ }^{*} 1501$-negative MS patients and the second included MS patients who were HLADR1*1501 positive for at least one allele. One hundred and ninety-one patients were positive for the DRB ${ }^{\star} 1501$ allele (24 homozygous and 167 heterozygous) and 177 were negative. After stratification of MS patients by carriage of HLA-DRB ${ }^{*} 15$ allele, no marker or haplotype 
Table 1 Comparison of studies by Martinez et al and Couturier et al

\begin{tabular}{|c|c|c|c|c|}
\hline & \multicolumn{2}{|c|}{ KCNH7, rs2068330 } & \multicolumn{2}{|c|}{ IFIH1, rs 1990760} \\
\hline & $C$ & $G$ & $A$ & $G$ \\
\hline \multicolumn{5}{|l|}{ Martinez et $a f^{\beta}$} \\
\hline Controls & $660(61.7 \%)$ & $410(38.3 \%)$ & $630(58.9 \%)$ & $440(41.1 \%)$ \\
\hline \multirow[t]{2}{*}{ MS patients } & $568(68.9 \%)$ & $256(31.1 \%)$ & $523(63 \%)$ & $307(37 \%)$ \\
\hline & \multicolumn{2}{|c|}{$\begin{array}{l}\text { G vs } C, O R=0.73 \\
(0.6-0.88) ; P=0.001\end{array}$} & \multicolumn{2}{|c|}{$\begin{array}{l}G \text { vs } A, O R=0.84 \\
(0.7-1.02) ; P=0.07\end{array}$} \\
\hline \multicolumn{5}{|l|}{ Couturier et $a l^{b}$} \\
\hline Controls & 1499 (63.6\%) & 859 (36.4\%) & $1427(60.4 \%)$ & 934 (39.6\%) \\
\hline MS patients & \multicolumn{2}{|c|}{$\begin{array}{l}\text { G vs } C, O R=0.96 \\
(0.83-1.11) ; P=0.5\end{array}$} & \multicolumn{2}{|c|}{$\begin{array}{l}\text { G vs } \mathrm{A}, \mathrm{OR}=0.97 \\
(0.84-1.12) ; P=0.72\end{array}$} \\
\hline
\end{tabular}

MS, multiple sclerosis; OR, odds ratio.

a Martinez et al is a case-control study.

${ }^{b}$ Couturier et al is a family-based study. Therefore, the control cohort is made up of the parents in trio families.

Table 2 Association analysis of the IFIH1 SNP rs 1990760 (A946T) in 591 French MS trio families

\begin{tabular}{lccc}
\hline & $\begin{array}{c}\text { Transmitted, } \\
\text { N (\%) }\end{array}$ & $\begin{array}{c}\text { Untransmitted }^{\mathrm{a}}, \\
\mathrm{N}(\%)\end{array}$ & P-value \\
\hline Allele A & $287(51.6)$ & $269(48.4)$ & 0.45 \\
\hline
\end{tabular}

antransmitted (pseudocontrol) genotypes are estimated.
Table 3 Association analysis of the $\mathrm{KCNH7}$ SNP rs2068330 in 591 French MS trio families

\begin{tabular}{lccc}
\hline & $\begin{array}{c}\text { Transmitted, } \\
\text { N (\%) }\end{array}$ & $\begin{array}{c}\text { Untransmitted }^{\mathrm{a}}, \\
\mathrm{N}(\%)\end{array}$ & P-value \\
\hline Allele C & $283(52.4)$ & $257(47.6)$ & 0.27
\end{tabular}

antransmitted (pseudocontrol) genotypes are estimated.

Table 4 Analysis of rs1990760/rs2068330 haplotypes in 591 French MS trio families

\begin{tabular}{|c|c|c|c|c|c|}
\hline & rs1990760 & rs2068330 & Transmitted, N (\%) & $\begin{array}{l}\text { TDT } \\
\text { Untransmitted }^{\mathrm{a}}, \mathrm{N}(\%)\end{array}$ & P-value \\
\hline $\begin{array}{l}\text { Haplotype } 1^{\mathrm{b}} \\
\text { Haplotype } 2^{\mathrm{b}} \\
\text { Haplotype } 3^{\mathrm{b}}\end{array}$ & $\begin{array}{l}A \\
G \\
G\end{array}$ & $\begin{array}{l}\mathrm{C} \\
\mathrm{G} \\
\mathrm{C}\end{array}$ & $\begin{array}{r}293(51.5) \\
249(47.8) \\
77(52.4)\end{array}$ & $\begin{array}{r}276(48.5) \\
272(52.2) \\
70(47.6)\end{array}$ & $\begin{array}{l}0.47 \\
0.32 \\
0.55\end{array}$ \\
\hline
\end{tabular}

TDT, transmission/disequilibrium test.

aUntransmitted (pseudocontrol) genotypes are estimated.

${ }^{b}$ Haplotypes with a frequency $>5 \%$.

of the IFIH1-GCA-KCNH7 locus was significantly associated with disease susceptibility (data not shown).

\section{Discussion}

The human IFIH1-GCA-KCNH7 locus is located on chromosome 2q24-3 and encodes for a key protein in the type 1 interferon (IFN) pathway. Therefore, it is a potential key player in MS pathogenesis. The IFIH1 gene has been implicated as a susceptibility gene in other autoimmune diseases, such as type I diabetes ${ }^{17}$ or Graves' disease. ${ }^{18}$ Common genetic variants have been implicated in various autoimmune diseases or in families with several cases affected by different diseases. ${ }^{19,20}$ It is of interest to note that the IFIH1-GCA-KCNH7 locus was not a region of interest in a recent first genome-wide association scan in MS. Nevertheless, the authors stated that it was 'likely that other loci with similar low-risk ratios exist'. That is why a consortium was formed to increase the number of patients available worldwide. Altogether, we believe that IFIH1-GCA-KCNH7 locus is a good susceptibility locus for genetic susceptibility to MS.

We failed to replicate the initial positive association between IFNIH1-GCA-KCNH7 locus and MS found by Martinez et al. It is obvious that a different ethnic background between French and Spanish patients could explain such a discrepancy. Nevertheless, alternative explanations may exist. First, we used a different, familybased approach. It is widely accepted that family studies 
permit both linkage and association analyses and decrease the potential for false-positive findings because of population substructure. This raises the possibility that Martinez et al's finding may be related to a type I error. ${ }^{21}$ Second, the discrepancy may be related to our study's power to detect small genetic effects. We calculated the power to detect genotype relative risks of 1.73 (homozygotes) and 1.16 (heterozygotes) under two scenarios. First, with a type I error of $5 \%$ (for a two-tail test), the power was $79.5 \%$. The second scenario was for a type I error of $10 \%$, which is acceptable in a context of a replication study (one-way test). Here, the power becomes $87.3 \%$. Although our cohort power may be considered as acceptable, we cannot exclude the possibility that our negative replication may be because of an underpowered study.

In conclusion, our negative replication is of interest in the framework of the effort that is necessary before it can be confirmed, or not, that the IFIH1-GCA-KCNH7 locus is a genuine locus for genetic susceptibility to MS.

\section{Acknowledgements}

We thank the French MS genetics Network REFGENSEP for their help and support. This work could not have been carried out without the SNP technology performed in the genomic platform of Genopole Toulouse Midi Pyrénées. The financial support of ARSEP (Association pour la recherche sur la Sclérose en plaques) is acknowledged.

\section{References}

1 Brassat D, Oksenberg J: Genetics of multiple sclerosis; in Research signpost (eds):: Molecular Bases of Neurodegeneration 2005, pp $43-49$.

2 Dyment DA, Ebers GC, Sadovnick AD: Genetics of multiple sclerosis. Lancet Neurol 2004; 3: 104-110.

3 Hafler DA, Compston A, Sawcer S et al: Risk alleles for multiple sclerosis identified by a genomewide study. N Engl J Med 2007; 357: 851-862.

4 Lundmark F, Duvefelt K, Iacobaeus E et al: Variation in interleukin 7 receptor alpha chain (IL7R) influences risk of multiple sclerosis. Nat Genet 2007; 39: 1108-1113.
5 Gregory SG, Schmidt S, Seth P et al: Interleukin 7 receptor alpha chain (IL7R) shows allelic and functional association with multiple sclerosis. Nat Genet 2007; 39: 1083-1091.

6 Harley JB: IL-7Ralpha and multiple sclerosis risk. Nat Genet 2007; 39: $1053-1054$

7 Ramagopalan SV, Anderson C, Sadovnick AD, Ebers GC: Genomewide study of multiple sclerosis. N Engl J Med 2007; 357: 2199-2201.

8 Weber F, Fontaine B, Cournu-Rebeix I et al: IL2RA and IL7RA genes confer susceptibility for multiple sclerosis in two independent European populations. Genes Immun 2008; 9: 259-263.

9 Chanock SJ, Manolio T, Boehnke $M$ et al: Replicating genotypephenotype associations. Nature 2007; 447: 655-660.

10 Skol AD, Scott LJ, Abecasis GR, Boehnke M: Joint analysis is more efficient than replication-based analysis for two-stage genomewide association studies. Nat Genet 2006; 38: 209-213.

11 Barnetche T, Constantin A, Cantagrel A, Cambon-Thomsen A, Gourraud PA: New classification of HLA-DRB1 alleles in rheumatoid arthritis susceptibility: a combined analysis of worldwide samples. Arthritis Res Ther 2008; 10: R26.

12 Martinez A, Santiago JL, Cenit MC et al: IFIH1-GCA-KCNH7 locus: influence on multiple sclerosis risk. Eur J Hum Genet 2008; advance online publication.

13 Goodkin DE, Doolittle TH, Hauser SS, Ransohoff RM, Roses AD, Rudick RA: Diagnostic criteria for multiple sclerosis research involving multiply affected families. Arch Neurol 1991; 48: 805-807.

14 Poser CM, Paty DW, Scheinberg L et al: New diagnostic criteria for multiple sclerosis: guidelines for research protocols. Ann Neurol 1983; 13: 227-231.

15 Polman CH, Reingold SC, Edan G et al: Diagnostic criteria for multiple sclerosis: revisions to the 'McDonald Criteria. Ann Neurol 2005; 58: 840-846.

16 Barrett JC, Fry B, Maller J, Daly MJ: Haploview: analysis and visualization of LD and haplotype maps. Bioinformatics 2005; 21: $263-265$.

17 Smyth DJ, Cooper JD, Bailey R et al: A genome-wide association study of nonsynonymous SNPs identifies a type 1 diabetes locus in the interferon-induced helicase (IFIH1) region. Nat Genet 2006; 38: 617-619.

18 Sutherland A, Davies J, Owen CJ et al: Genomic polymorphism at the interferon-induced helicase (IFIH1) locus contributes to Graves' disease susceptibility. J Clin Endocrinol Metab 2007; 92: $3338-3341$.

19 Pearce SH, Merriman TR: Genetic progress towards the molecular basis of autoimmunity. Trends Mol Med 2006; 12: 90-98.

20 Hauser S, Oksenberg J, Brassat D: Genetics of immune-mediated neurologic diseases. Clinical Neuroimmunology. Oxford University Press, 2005.

21 Clayton DG, Walker NM, Smyth DJ et al: Population structure, differential bias and genomic control in a large-scale, casecontrol association study. Nat Genet 2005; 37: 1243-1246. 